\title{
Preferencias, dedicación y problemáticas generadas por los videojuegos: Una perspectiva de género
}

\section{Preferences, dedication and problematics generated by video games: A gender perspective}

Recibido: Febrero 2015

\author{
Carmen RICOY y Aida AMENEIROS \\ Universidad de Vigo
}

Evaluado: Abril 2015

Aceptado: Abril 2015

\section{Resumen}

Entre las actividades de ocio de los/as jóvenes, cabe mencionar las asociadas con los videojuegos. Por ello, la finalidad central de este estudio es analizar las preferencias del colectivo de adolescentes con los videojuegos, así como conocer su dedicación y problemáticas que generan, teniendo en cuenta principalmente la variable de género. El presente trabajo se encuadra en un enfoque metodológico cuantitativo-cualitativo, a partir de la recogida de datos con un cuestionario y la técnica del grupo de discusión. En el estudio han participado un total de 151 adolescentes. 124 a partir de la aplicación de un cuestionario cerrado (62 hombres y 62 mujeres) y 27 a través de la realización de 6 grupos de discusión (17 hombres y 10 mujeres). Como resultados y conclusiones, cabe destacar la existencia diferenciada en el uso de los videojuegos en función de la edad y por razón de género. A su vez, las mujeres muestran una responsabilidad mayor en esta actividad, tanto en el tiempo de dedicación como en la elección. Los chicos destinan una gran cantidad de tiempo a los videojuegos de contenido violento, mientras las chicas prefieren los de estrategia. En general, el juego con videojuegos no genera problemáticas sustanciales y controversias, aunque algunos participantes reflejan manifestaciones de mal humor. Por último, cabe indicar que las prácticas con los videojuegos en la adolescencia se ciñen al mero hecho de divertirse, desperdiciando las posibilidades educativas que esta actividad ofrece.

Palabas clave: videojuegos, adolescentes, preferencias, videoconsolas, educación.

\begin{abstract}
Among the leisure activities of young boy/girls, it should be mentioned those associated with video games. Therefore, the central purpose of this study is to analyze the preferences of the group of adolescents with video games, as well as to know their dedication and problematics generated mainly considering the gender variable. This work is framed in a quantitativequalitative methodological approach, based on data collection with a questionnaire and the focus group technique. A total of 151 adolescents were involved in the study. 124 from the application of a closed questionnaire (62 men and 62 women) and 27 through the realization of 6 focus groups (17 men and 10 women). As results and conclusions, it is worth highlighting the existence of a distinct use of video games according to age and gender. In turn, women show greater responsibility with this activity, both in the time of dedication as in the election. Boys


dedicate a lot of time to violent content video games, while girls prefer the strategy ones. In general, the game with video games does not generate substantial problematics and controversies, although some of the participants reflect bad humor's manifestations. Finally, it must be indicated that video games practices in adolescence are limited to the mere fact of having fun, wasting the educational possibilities that this activity offers.

Keywords: videogames, teenagers, preferences, videogame console, education.

En la actualidad los videojuegos se encuentran entre las actividades de entretenimiento de los adolescentes. Es habitual ver a las personas más jóvenes jugando con videojuegos en el hogar, y sin embargo apenas nos encontramos con el panorama existente antaño en las calles supeditado a los juegos tradicionales. Es obvio que también los juegos forman parte del patrimonio cultural de una época (Huizinga, 2007; Wittgenstein, 2008). No obstante, pueden producirse saltos importantes que provocan cambios acentuados en el ámbito del ocio. Estas transformaciones son motivo de la preocupación de diferentes colectivos de profesionales, de las familias y de la comunidad científica ante las posibles preferencias y problemáticas que los dispositivos tecnológicos pueden generar en las personas más vulnerables.

El juego es una práctica de tipo social con gran importancia para el desarrollo de la vida de las personas en las primeras etapas, en particular en la de la infancia. Cabe indicar que el juego se debe caracterizar por ser una actividad: libre y voluntaria; improductiva (es el propio juego y no el producto final lo que interesa); placentera; ficticia; limitada en el tiempo y en el espacio (con un principio y un fin); y regularizada por un conjunto de normas (Gómez del Castillo, 2007; Sauquillo, Ros y Bellver, 2008). Existen diferentes tipos de cualidades, a tener en cuenta en esta práctica, como el contacto directo o la experiencia generada por la convivencia que posibilita. Cabe referir que existen claros distintivos entre los juegos tradicionales y los videojuegos. Con todo, actualmente son los videojuegos los que poseen un fuerte atractivo y producen una gran motivación en niños/as y adolescentes.

Los videojuegos al igual que otros medios o aparatos, como el retroproyector, nacieron asociados al contexto militar. De modo que, el primer videojuego está relacionado con un simulador de vuelo para el conocimiento de técnicas básicas de pilotaje y su posterior entrenamiento militar (Ministerio de Educación y Ciencia, 2004). En la actualidad se considera que el precursor del videojuego fue Willy Higinbothan, quien en 1958 creó un juego de tenis utilizando gráficos muy simples (Tejeiro y Pelegrina, 2003). Desde entonces hasta la actualidad, la evolución de estos dispositivos ha sido incesante, así como el incremento del número de usuarios/as.

\section{Fundamentación y estudios sobre la temática}

Nuestro país ocupa el cuarto puesto en el mercado europeo con la consumición de videojuegos. De hecho Garrido (2013) sostiene que los videojuegos representan la principal práctica social vinculada con el ocio. No obstante, aunque se le atribuyan diferentes críticas, son una de las fórmulas más atractivas para ocupar el tiempo libre 
debido al interés que suscitan. Cabe indicar que como actividad de ocio los videojuegos brindan posibilidades novedosas y generan una fuerte persuasión en las personas jóvenes desbancando con creces, como ya apuntamos, a los juegos tradicionales. Sin embargo, las prácticas con los videojuegos frente a las desarrolladas con los juegos tradicionales pueden contribuir, en mayor medida, a originar efectos nocivos. Por ello, para prevenir las posibles ilaciones la implicación de la familia adquiere un papel importantísimo. En este sentido, existen evidencias de que el control parental en el tiempo de dedicación al videojuego y sobre el contenido del mismo va asociado a un perfil de jugador/a no problemático y responsable en la elección de la tipología (Lloret et al., 2013). Otro aspecto a considerar en el videojuego, según Pérez Latorre (2010), es que se distingue del juego tradicional principalmente por sus características digitales y audiovisuales, junto a la interfaz y al dispositivo utilizado.

Las peculiaridades que presentan los videojuegos suscitan la motivación de las personas, pero pueden llegar a conquistar su voluntad. Con todo, siendo los estímulos lúdicos componentes valiosos para integrar en el proceso de enseñanza-aprendizaje, el videojuego es susceptible de incluir como recurso didáctico en el ámbito escolar (Marín y Párraga, 2014). De hecho, los dispositivos digitales juegan un papel muy importante, tanto en las prácticas de ocio, como en las de aprendizaje. Asimismo la integración de las TIC en el currículum escolar es de gran utilidad, aunque un uso excesivo y/o mal orientado podría repercutir negativamente, llegando a disminuir el rendimiento académico (Mößle et al., 2010; Sharif, Wills y Sargent, 2010).

El sedentarismo, el bajo rendimiento escolar y los trastornos de conducta son los efectos negativos de los videojuegos que en la actualidad preocupan principalmente a las familias y a los educadores/as. De hecho, Anderson et al. (2010) consideran muy perjudiciales las secuelas de los videojuegos y plantean analizarlas a partir de las conductas agresivas que provocan la obcecación cognitiva y emocional, la excitación fisiológica, la empatía y otras actitudes pro-sociales o anti-sociales generadas. Los vídeo-jugadores suelen buscar en esta práctica estímulos que les hagan sentir bien y que, a su vez, favorecen la adicción con las hormonas que le segregan (Muros, Aragón y Bustos, 2013). Los videojuegos suponen una vía de escape, ante situaciones estresantes o que producen ansiedad o agotamiento, como consecuencia de una vida ajetreada. Por ello, resulta insólito que la dependencia que, esta nueva forma de ocio, produce en los adolescentes españoles resulte similar a la generada en los de los Estados Unidos, aunque éstos últimos se encuentren mucho más influenciados por las nuevas tecnologías (Hart et al., 2009).

Se entiende que se produce adicción cuando el videojuego se convierte en uno de los principales pensamientos y acciones en la vida de la persona, alterando tanto sus hábitos y actividades rutinarias como sus relaciones sociales. Distintos estudios, como el realizado por Marco y Chóliz (2014), han puesto de manifiesto la necesidad de un tratamiento psicológico centrado en la adicción a videojuegos. De este modo la adicción producida, particularmente, por los videojuegos de MMORPG adquiere un reconocimiento que hasta ahora había pasado inadvertido. Por su parte, Hussain y Griffits (2009) demuestran la incidencia de la dependencia a los videojuegos a partir del descuido de ciertos hábitos relacionados con la: higiene, comida, trabajo y escuela. 
Lorca (2006) indica que en las ciudades grandes, como Madrid, algunas personas presentan una situación preocupante al refugiarse en los videojuegos. De hecho, detectó que un $43,9 \%$ de la comunidad de jugadores/as tuvo algún problema a causa del juego, un 20,6\% mantiene discusiones con la familia, un 15,3\% duerme menos y un $14,3 \%$ olvida sus compromisos cotidianos. Asimismo, este autor sostiene que la dependencia comportamental en la adolescencia está asociada a los juegos en línea. No obstante, la adicción a los videojuegos puede ser un problema generalizado, susceptible de afectar a cualquier persona.

En otro orden de cuestiones, algunos estudios han puesto de manifiesto que, desde el entorno familiar el seguimiento, del tiempo que dedican a los videojuegos sus hijos y/o hijas, es prácticamente nulo (Muros et al., 2013; Tolsá y Bringué, 2012; Ward, 2010). El fuerte rol autoritario ejercido en el pasado en la tutela se ha relajado considerablemente en la actualidad. Este hecho repercute en la educación de las nuevas generaciones de los/as menores, que pueden sentir cierto descontrol y decidir, por sí mismos/as, el tiempo que dedican a los videojuegos. Sin embargo, la gestión del tiempo y la orientación en el desarrollo de estas prácticas requiere del acompañamiento de la persona adulta.

Independientemente de que deben considerarse los efectos nocivos de los videojuegos también éstos pueden proporcionar aspectos positivos. En este sentido Ferrer y Ruíz (2005) apuntan que su uso adecuado podría ser un buen complemento en la formación, ayudando a reforzar la autoestima o robusteciendo las relaciones sociales; sus prácticas poseen un gran potencial para la transmisión y/o asimilación de normas, conceptos y valores. Moreno y García Serrano (2006) señalan algunos aspectos que los videojuegos ayudan a desarrollar: capacidad de atención y concentración, habilidades para el trabajo en grupo, mejora de las estrategias para la resolución de conflictos, agudeza mental para la toma de decisiones y comprensión de conceptos abstractos. Redick y Webster (2014) sostienen que, en los últimos años, surge la idea de que los videojuegos son beneficiosos para mejorar funciones cognitivas en los usuarios/as. Asimismo, pueden resultar de interés para compartir afinidades y el tiempo libre, o para mejorar la calidad de vida.

Por otra parte, cabe indicar que entre los videojuegos más comunes, siguiendo a Griffiths, Davies y Chappell (2004), se encuentran los conocidos como Massively Multiplayer Online Role-Playing Game (MMORPG), también llamados "videojuegos de rol multi-jugador online". En estos juegos el usuario/a cuenta con múltiples posibilidades asociadas a la: creación de personajes virtuales, exploración del entorno, desarrollo de habilidades del avatar, interacción con los coetáneos, etc. Hay que tener en cuenta que este tipo de videojuegos provoca la participación masiva de millones de personas que juegan simultáneamente de forma online (Marco y Chóliz, 2014). De hecho, sus atractivas características pueden incitar extremadamente al juego.

\section{Propósito del estudio}

La finalidad central de este trabajo es analizar las preferencias del colectivo de adolescentes ante los videojuegos, así como conocer la dedicación y las problemáticas 
que desencadena su práctica. Como objetivos específicos se han considerado los siguientes:

- Identificar el tipo de dispositivos utilizados por los/as adolescentes para jugar con los videojuegos.

- Revelar el tiempo que dedican a los videojuegos.

- Identificar los videojuegos preferidos por los/as adolescentes.

- Detectar el tipo de control parental ejercido con los/as menores en los videojuegos que utilizan.

- Desvelar las contingencias que generan los videojuegos.

Atendiendo a las finalidades de esta investigación, se presentó como hipótesis principal que los/as adolescentes prefieren jugar a los videojuegos de rol, con sus amigos/as, usando como soporte más común la consola. También se mantuvo que el uso excesivo de juego con videojuegos produce en este colectivo problemáticas que pueden incidir negativamente en su desarrollo. Asimismo se han considerado algunas variables de tipo personal (la edad y el género) y escolar (rendimiento académico).

\section{Metodología de investigación}

Esta investigación se encuadra en un enfoque bimetódico (cuantitativo-cualitativo). Esto permite profundizar en el estudio con la relación que se establece entre algunas variables. Se ha analizado la correspondencia o tipo de discordancia existente entre los resultados obtenidos en diferentes preguntas del cuestionario, con la información aportada por los grupos de discusión. En concreto, a través del análisis cuantitativo se consideró la relación establecida entre variables personales (asociadas con la edad de los participantes y el género) y escolares (en base al rendimiento académico a partir de la nota media) con el uso de los videojuegos; mientras que en el cualitativo se ha indagado fundamentalmente sobre la afinidad y divergencia que se produce con estas prácticas desde la perspectiva de género.

\section{Participantes}

La muestra de estudio se sitúa en dos instituciones educativas, de la Comunidad Autónoma de Galicia, una de titularidad pública y la otra privada. Los participantes proceden, en la aplicación del cuestionario, de un Instituto de Educación Secundaria (IES) y la realización de los grupos de discusión tuvo lugar con el alumnado de un centro concertado. Para acotar la muestra se realizó inicialmente, dentro del contexto de cada entidad, una selección aleatoria por el profesorado a través de un procedimiento sistemático. Con todo, se ha buscado cierto equilibrio en cuanto al género de los participantes, aunque en los grupos de discusión, no fue posible, el número de hombres resultó superior (17) al de mujeres (10). El colectivo objeto de la investigación quedó conformado por un total de 151 adolescentes. De ellos han cumplimentado un cuestionario 124 jóvenes (62 hombres y 62 mujeres) de un IES, con edades comprendidas entre 12 y 16 años ( $M=13,5645$ años). 
Para la recogida de información a través de 6 grupos de discusión se reunieron a los/as participantes, en cada uno, atendiendo a la disponibilidad de los/as mismos/as por curso académico o integrando alumnado de diferentes cursos de la ESO. En la composición siempre se opto por grupos mixtos, con chicos y chicas. En total han participado 27 adolescentes (17 hombres y 10 mujeres), con edades entre 12 y 17 años $(\mathrm{M}=13,962$ años). En los grupos de discusión se ha contado, en 3 de ellos, con 4 adolescentes y, en los 3 restantes, con 5 . La composición fue la siguiente:

- Grupo 1 ( $1^{\circ}$ y $2^{\circ}$ de la ESO), constituido por 1 hombre de 12 años, 2 de 13 años y 1 mujer también de 13 años.

- Grupo 2 ( $3^{\circ}$ de la ESO), comprendió a 3 hombres de 14 años y a 1 mujer de la misma edad.

- Grupo 3 ( $4^{\circ}$ de la ESO), configurado por 2 hombres de 16 años, uno de 17 y una mujer de 16 años.

- Grupo 4 ( $1^{\circ}$ de la ESO), compuesto por 3 hombres y 2 mujeres de 12 años.

- Grupo 5 ( $3^{\circ}$ y $4^{\circ}$ de la ESO), formado por 3 hombres y 2 mujeres de 14 años.

- Grupo 6 ( $4^{\circ}$ de la ESO), configurado por 2 hombres y 3 mujeres de 15 años.

\section{Instrumentos y análisis de datos}

Como se adelantó, en esta investigación se utilizaron dos instrumentos para la recogida de información, ambos diseñados ad hoc a partir del asesoramiento de distintos expertos/as o especialistas: Un doctor y una doctora, en Ciencias de la Educación, procedentes de diferentes universidades españolas; una Educadora Social; y una Profesora de Instituto. Estos profesionales realizaron distintas correcciones y sugerencias a la versión inicial del cuestionario y al guión de las preguntas planificadas para los grupos de discusión, posibilitando finalmente su optimización.

\section{Cuestionario}

El protocolo del cuestionario contó con 40 ítems (11 relativos a los datos de perfil y de contextualización). El cuerpo del instrumento comprende un total de 29 cuestiones, que se configuraron a partir de la categorización definida para cada pregunta. El cuerpo del cuestionario definitivo se estructuró en cuatro bloques, con ítems de carácter categorial, relativos a los:

- "Tipos de dispositivos y conexión a Internet", que consta de 5 ítems, 1 de carácter dicotómico y los 4 restantes presentan opciones para respuestas múltiples.

- "Tiempo dedicado a los videojuegos y control parental", recoge 4 cuestiones con ítems de respuesta única.

- "Preferencias y/o intereses", se configuró con 4 ítems (2 de respuesta única y las restantes con opciones múltiples).

- "Tipología de videojuegos y relaciones sociales", está conformado por 15 preguntas (2 para opciones múltiples y todos las demás de respuesta única). 
Para analizar los datos de las respectivas preguntas del cuestionario se utilizó el programa SPSS/20. A partir de él se calcularon los estadísticos descriptivos (frecuencias y porcentajes) y de contraste (Chi-Cuadrado - $\chi^{2}$ - y el grado de Probabilidad $-p-)$ ) para analizar diferentes relaciones, a partir de las variables de perfil y escolar (n. c. $95 \%$ y $p \leq 0,05$ ).

\section{Guión del grupo de discusión}

Los grupos de discusión fueron dinamizados por una de las autoras de este trabajo y la duración de cada uno giró en torno a 45 minutos. El guión de preguntas comprende, además de los datos de perfil, 8 cuestiones de tipo estructurado, para el debate con los y las adolescentes, con el objeto de facilitar inicialmente la agrupación de los datos obtenidos. Estas cuestiones se centraron en:

- Las horas de dedicación a los videojuegos.

- Los soportes/dispositivos utilizados con los videojuegos.

- Las preferencias manifestadas en el juego con videojuegos.

- El tiempo utilizado y las actividades que realizan con la familia y sus coetáneos.

- Desarrollo del juego con videojuegos con los compañeros/as y la familia.

- La posible repercusión de los videojuegos en sus relaciones sociales.

- El control ejercido por la familia ante los videojuegos.

- Las problemáticas desencadenadas a partir del juego con videojuegos.

El uso de esta técnica, de forma complementaria a la del cuestionario, ha sido interesante para profundizar, explicar, comprender e interpretar la información objeto de estudio. Además, se robusteció la fiabilidad de los datos mediante el uso de diferentes metodologías, con la recogida de información a través de distintas fuentes y de varios tipos de análisis. De este modo, se ha podido constatar el nivel de convergencia y divergencia de los resultados para poder garantizar su credibilidad (Tracy, 2010).

El análisis cualitativo se realizó con el programa de Analysis of Qualitative Data (AQUAD). Este software permitió profundizar en los análisis de contenido realizados. $\mathrm{Su}$ procedimiento ha pasado por distintas fases: a partir de las categorías definidas inicialmente (a través de las respectivas preguntas); la determinación y el recuento de las subcategorías extraídas (a partir de los datos brutos); y el análisis de contingencia, para determinar el tipo de asociación establecida entre variables cualitativas. Con todo, no interesa focalizar el interés de este análisis en sus componentes cuantitativos, aunque resultan de utilidad para conocer la tendencia y examinar las relaciones existentes o la disonancia que se establece con la utilización de los videojuegos, así como con sus problemáticas, en función del género.

\section{Resultados}

Los resultados presentados derivan de los análisis estadísticos y cualitativos desarrollados, aunque por cuestiones de espacio no puede presentarse en el presente 
artículo su totalidad. Seguidamente se exponen los principales resultados organizados en tres subapartados (atendiendo al colectivo de adolescentes objeto de estudio):

\section{Preferencias y tiempo dedicado a los videojuegos}

Los resultados estadísticos ponen de manifiesto que la actividad de ocio que más atrae a los adolescentes, además de salir con sus amistades $(89,5 \%)$, es jugar a videojuegos $(73,4 \%)$, existiendo significatividad estadística en función del género y la edad. De hecho, se revela que cuanto más elevada es la edad de los adolescentes mayor es la cantidad de los que tienen predilección por el juego con videojuego $\left(\chi^{2}=9,969\right.$; $p=0,041)$. Además, se detecta, de forma significativa $\left(\chi^{2}=9,291 ; p=0,002\right)$, que los hombres presentan mayor preferencia por los videojuegos que las mujeres.

\begin{tabular}{|c|c|c|c|c|c|c|c|}
\hline \multirow{2}{*}{\multicolumn{2}{|c|}{ Ítem }} & \multicolumn{6}{|c|}{ Horas continuadas que dedicas a los videojuegos } \\
\hline & & $<1$ Hora & $>1 \mathrm{H}$ & $>\mathbf{3 H}$ & $>5 \mathrm{H}$ & $\chi^{2}$ & $p$ (Prob.) \\
\hline \multirow{5}{*}{ Edad } & 12 años & $56,30 \%$ & $40,60 \%$ & $3,10 \%$ & $0,00 \%$ & \multirow{5}{*}{15,526} & \multirow{5}{*}{0,214} \\
\hline & 13 años & $31,30 \%$ & $59,40 \%$ & $6,30 \%$ & $3,10 \%$ & & \\
\hline & 14 años & $54,20 \%$ & $29,20 \%$ & $16,70 \%$ & $0,00 \%$ & & \\
\hline & 15 años & $50,00 \%$ & $30,00 \%$ & $13,30 \%$ & $6,70 \%$ & & \\
\hline & 16 años & $66,70 \%$ & $33,30 \%$ & $0,00 \%$ & $0,00 \%$ & & \\
\hline \multirow[b]{2}{*}{ Género } & Hombre & $29,00 \%$ & $48,40 \%$ & $17,70 \%$ & $4,80 \%$ & \multirow[b]{2}{*}{25,600} & \multirow[b]{2}{*}{0,000} \\
\hline & Mujer & $67,70 \%$ & $32,30 \%$ & $0,00 \%$ & $0,00 \%$ & & \\
\hline \multirow{5}{*}{$\begin{array}{l}\text { Nota } \\
\text { media } \\
\text { escolar }\end{array}$} & $>8$ & $56,80 \%$ & $37,80 \%$ & $5,40 \%$ & $0,00 \%$ & \multirow{4}{*}{12,694} & \multirow{4}{*}{0,177} \\
\hline & $6-8$ & $47,90 \%$ & $45,80 \%$ & $6,30 \%$ & $0,00 \%$ & & \\
\hline & $5-6$ & $42,30 \%$ & $30,80 \%$ & $19,20 \%$ & $7,70 \%$ & & \\
\hline & $<5$ & $38,50 \%$ & $46,10 \%$ & $7,70 \%$ & $7,70 \%$ & & \\
\hline & & & & & & & $N=124$ \\
\hline
\end{tabular}

Tabla 1. Relación del perfil personal y escolar con la dedicación a los videojuegos

En cuanto a la frecuencia de uso de los videojuegos se revela diferencia significativa en función del género $\left(\chi^{2}=8,297 ; p=0,040\right)$. Los chicos muestran mayor asiduidad que las chicas, ya que un $9,70 \%$ de hombres frente a un $3,20 \%$ de mujeres juegan todos los días; mientras el $16,10 \%$ de las chicas y el 3,2\% de los chicos nunca desarrolla esta actividad. Asimismo, aunque sin que se constate significatividad estadística, los/as participantes que más tiempo juegan con los videojuegos son los que tienen unas calificaciones académicas inferiores. Con relación a la variable sobre las horas dedicadas, de forma continuada, a los videojuegos por género existe diferencia estadísticamente significativa $\left(\chi^{2}=25,600 ; p=0,000\right)$. Los chicos dedican entre 3 y 5 horas, mientras que la mayoría de las chicas destina menos de 1 hora (tabla 1).

Respecto a las horas que dedican a los videojuegos en días laborales, los resultados cualitativos indican al igual que los cuantitativos, aunque con matices, la existencia de 
una notable divergencia en función del género. En el caso de las mujeres se detecta que juegan a los videojuegos un máximo de dos horas en días laborales, sin embargo los hombres llegan a dedicarle hasta siete horas. En relación al tiempo destinado a los videojuegos durante el fin de semana se descubre que los chicos juegan mucho más que las chicas. Existe una predisposición acentuada en los hombres a jugar una elevada cantidad de horas (entre $4-5 \mathrm{~h}$ diarias), y además se determina que algunos adolescentes llegan a jugar hasta 10 y 15 horas durante el fin de semana. Este hecho, muestra que la ocupación del tiempo libre, del que gozan estos jóvenes, en el fin de semana se subyuga, en diversos casos, únicamente a interactuar con los videojuegos o a través de ellos. Este hecho, denota que no realizan una buena gestión del tiempo libre, ni desarrollan prácticas de ocio saludables.

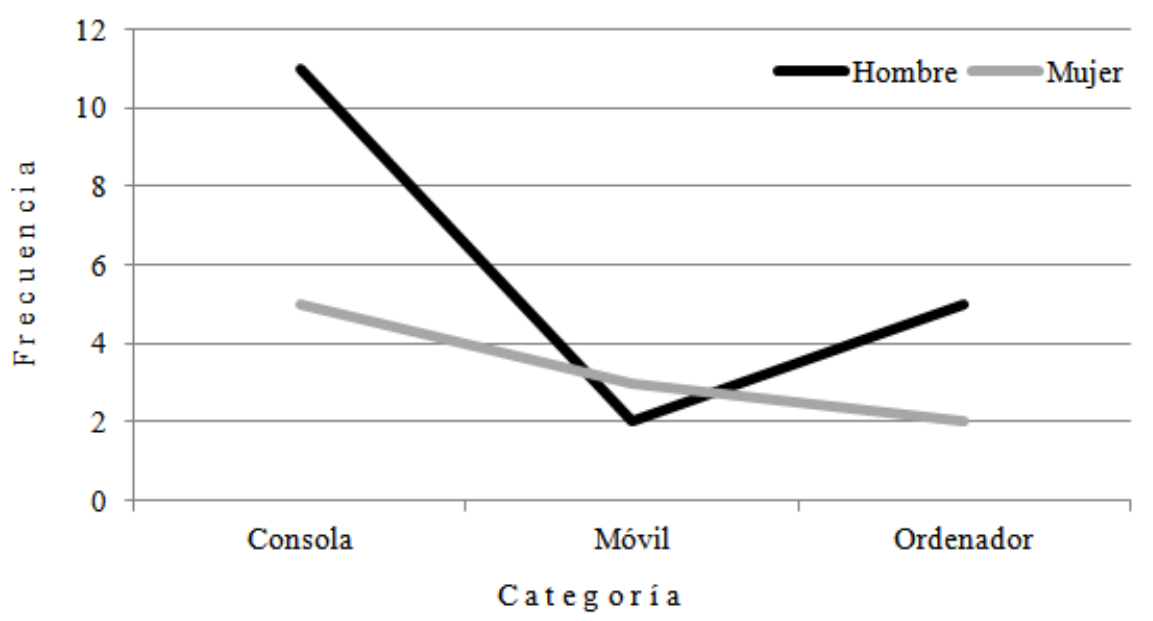

Figura 1. Preferencias por los dispositivos para jugar a los videojuegos

Los resultados cualitativos ponen de manifiesto que la tipología de dispositivo utilizado, de forma preponderante para jugar con los videojuegos, es la consola. Con todo, se detecta de modo subsidiario el uso de otros aparatos, existiendo distinción en función del género de los participantes. Con todo, a pesar de que, de forma notoria el colectivo muestra preferencia por utilizar la consola en los videojuegos, en segundo lugar los chicos optan por el ordenador y las chicas por el móvil (figura 1). En relación a la propensión por compartir los videojuegos se decantan por jugar con personas cercanas: amigos/as o hermanos; y excepcionalmente con los padres y madres. A modo de ejemplo, pueden observarse los siguientes fragmentos:

Yo he jugado tanto con mis amigos/as como con mis padres y mi hermano; y hemos jugado tanto con el móvil, como con el ordenador o la consola Wii (grupo 5, línea 90-92, mujer, $4^{\circ}$ ESO, 16 años).

Yo juego con la Play Station con mis amigos en Internet, porque tengo unos cascos, y a través de la consola puedo hablar con ellos (grupo 1, línea 102-104, hombre, $1^{\circ} \mathrm{ESO}, 12$ años). 
Los resultados estadísticos, al igual que los cualitativos, revelan que los y las adolescentes denotan predilección por compartir con sus amistades, principalmente dentro del grupo de iguales, los videojuegos $(73,4 \%)$. Sin embargo, no existen diferencias significativas entre la preferencia de la compañía en el juego con videojuegos y las variables de perfil (edad y género) o la nota media académica. Con todo, cabe señalar que los resultados evidencian que también el alumnado $(38,50 \%)$ que presenta una mayor inclinación por jugar en solitario cuenta con una nota media académica inferior. Además, hay que señalar que, solamente los chicos $(3,20 \%)$ manifiestan inclinación por jugar a los videojuegos con desconocidos/as.

\section{Videojuegos utilizados por los y las adolescentes}

A partir del estudio cualitativo se desprende que en los videojuegos, más utilizados, en la adolescencia existe una acentuada diferencia en función del género. Los chicos presentan una notoria preferencia por los de la FIFA, un clásico juego futbolístico, que se revela como estereotipo de género. Cuyo énfasis se agranda entre los participantes al posibilitarle el juego la inclusión de personajes con vinculación real y de actualidad.

Entre los chicos, con una distinción similar a los de la FIFA, se popularizan también los videojuegos conocidos como Grand Theft Auto (GTA). En estos juegos, de entorno abierto, los adolescentes valoran principalmente las oportunidades para manipularlo con libertad. Revelan que les resultan atractivos fundamentalmente por los componentes de acción y aventura que integran, así como por el ambiente de violencia y fantasía en el que les sumergen. Asimismo, argumentan su entusiasmo hacia los mismos en base a las acciones excitantes que presentan, al permitirle crear y sentir, con constituyentes agresivos, experiencias de poderío ficticio. La interacción con las "armas" y con otros mecanismos irascibles re-afirman que le resultan apasionantes.

También a partir del análisis cualitativo, cabe señalar que las chicas no muestran la misma predilección que los chicos hacia los videojuegos. Ellas, se decantan esencialmente por juegos como los de Candy Crush (figura 2). Se trata de un videojuego de estrategia ofertado para todas las edades, cuyas características se diferencian mucho de los elegidos por el colectivo masculino. Su formato no presenta las mismas contingencias que un juego de "mundo abierto", la interfaz es sencilla y similar a la del clásico Tetris. Las chicas indican que la propia familiarización que les permite, les genera cierto encanto y agrado. Con todo, este videojuego no les "engancha" con la magnitud que les ocurre, con los de la FIFA o los GTA (con contenidos violentos), a los chicos. A modo de ejemplo se ofrecen algunos extractos:

Mis videojuegos preferidos son los de Call of Duty y los de GTA. Porque en los de GTA tienes un mundo de cosas que hacer (...) y los de Call of Duty me gustan porque entretienen mucho y como son online tienes que estar más atento de lo que pasa (grupo 1, línea 144-150, hombre, $1^{\circ} \mathrm{ESO}, 12$ años).

Yo a los que más juego son a los videojuegos que tengo descargados en el móvil, sobre todo, los de Candy Crush y al de Apalabrados. Son muy entretenidos y no me 
resultan extraños, me hago rápidamente con su entorno (grupo 6, línea 103-105, mujer, $3^{\circ} \mathrm{ESO}, 15$ años).

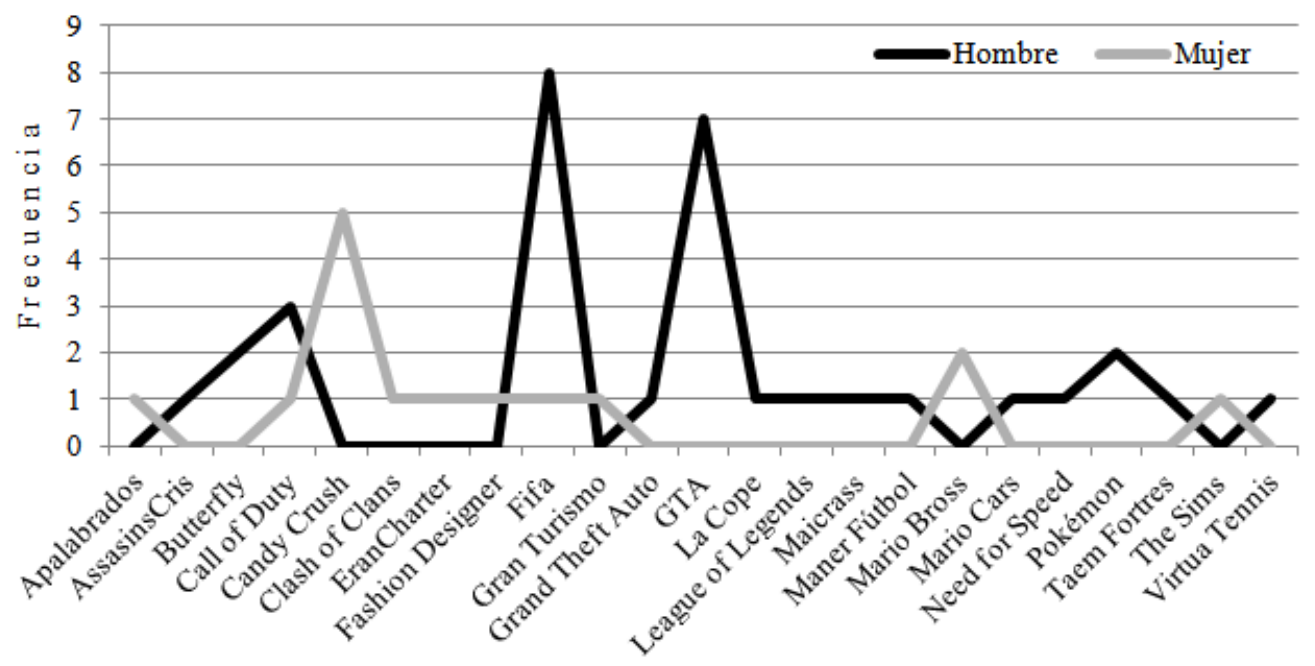

Categoría

Figura 2. Correspondencia entre los videojuegos utilizados y el género

Por su parte, los resultados estadísticos demuestran que sólo en algunos casos los usuarios que utilizan un elevado tiempo de dedicación a los videojuegos están sometidos al control de personas adultas. Los videojuegos más usados por los chicos son los que integran mayores componentes violentos y están clasificados para su uso por mayores de 18 años. Un 34,7\% de adolescentes están controlados por una persona adulta en su dedicación temporal al juego y en el tipo de contenido; mientras un 36,3\% sólo en alguna ocasión perciben este control; y un 29\% no experimenta supervisión alguna.

A partir de los análisis cualitativos se descubre que la familia apenas interviene para orientar o inducir a sus hijos e hijas hacia el uso de unos u otros videojuegos, ni ejerce un control sustancial sobre el tiempo que le dedican. Con todo, se detecta que existe una sutil intervención en la supervisión del tiempo que dedican, frente a la excepcional vigilancia que realizan sobre la tipología de videojuegos que manejan. En el caso de aquellos/as adolescentes que se refieren a la ausencia de control, por parte de su familia, no la perciben como relevante. En lo relativo a estos aspectos, a continuación se muestran algunos argumentos aportados por los participantes:

A veces se puede enfadar nuestra familia si nos pasamos jugando a los videojuegos porque tenemos que estudiar, pero mi padre y mi madre piensan que si nos esforzamos, tenemos derecho a escoger lo que queremos hacer en nuestro tiempo libre (grupo 1, línea 192-195, mujer, $1^{\circ}$ ESO, 12 años).

No ..., a mí habitualmente no me controlan ni el tiempo ni el tipo de videojuego que utilizo, aunque si alguna tarde me paso muchas horas me suelen decir algo, pero muy pocas veces. 
No tengo ningún problema por esto con mi familia (grupo 4, línea 156-158, hombre, $4^{\circ}$ ESO, 15 años).

\section{Problemáticas generadas por los videojuegos}

Los resultados procedentes de los análisis estadístico aportan evidencias sobre las problemáticas que reflejan los/as adolescentes frente a los videojuegos (tabla 2). De los datos obtenidos se desprende que no manifiestan alteraciones importantes de carácter aunque no puedan jugar con los videojuegos (76,6\%); sólo un 3,2\% de los/as participantes revelan mal humor cuando se les impide el desarrollo de esta práctica.

\begin{tabular}{lrrr}
\hline \multicolumn{1}{c}{ Ítem } & & F & $\mathbf{\%}$ \\
\hline ¿Te pones de mal humor si no & Sí & 4 & 3,2 \\
puedes jugar con tu videojuego & No & 95 & 76,6 \\
favorito? & A veces & 25 & 20,2 \\
\hline Si alguien te habla mientras & Sí & 56 & 45,2 \\
juegas, ¿prestas atención? & No & 13 & 10,5 \\
\hline Si alguien te gana en tu & A veces & 55 & 44,4 \\
videojuego preferido, ¿lo/a & Sí & 55 & 44,3 \\
felicitas? & No & 27 & 21,8 \\
& A veces & 42 & 33,9 \\
Si alguien necesita ayuda cuando & Sí, siempre & 63 & 50,8 \\
estás jugando ¿te ofreces? & No, nunca & 3 & 2,4 \\
& Depende de la persona & 43 & 34,7 \\
& Depende del tiempo & 15 & 12,1 \\
\hline
\end{tabular}

Tabla 2. Posicionamiento ante el juego con los videojuegos

Los datos cuantitativos (tabla 2) muestra que los/as participantes, aunque estén plenamente inmersos en el videojuego, prestan interés por las otras personas cuando reclaman su atención. En este sentido, existe similitud entre el número de participantes que brindan siempre que se le reclama atención $(45,2 \%)$, con aquellos que la mantienen en alguna ocasión (44,4\%). A su vez, se obtiene un porcentaje similar en los/as que felicitan al contrincante cuando éste/a le vence en el videojuego (44,3\%) y de aquellos/as que lo hacen sólo alguna vez (33,9\%). Por último, cabe destacar que el $50,8 \%$ de los/as adolescentes, aun jugando con los videojuegos, ofrecen ayuda cuando alguien la necesita o se la solicita; mientras un $34,7 \%$ solamente la proporciona de forma condicionada, dependiendo de la persona de la que se trate.

Del estudio realizado se desprenden resultados estadísticamente significativos con los/as participantes que pierden jugando con los videojuegos y felicitan al contrincante con la nota media académica obtenida $\left(\chi^{2}=13,055 ; p=0,042\right)$. Los datos revelan que, en mayor cantidad, son los adolescentes con la nota media académica de suspendo los que nunca felicitan a sus compañeros/as de juego (46,20\%). En contraposición, es en el alumnado $(59,5 \%)$ con una mejor media académica dónde se encuentra una predisposición mayor a elogiar a sus contrincantes/as.

A partir de los análisis de contenido se descubre alguna problemática vinculada con los videojuegos, poniéndose de manifiesto cierta disonancia entre los participantes, en 
función del género. Las mujeres muestran mayor responsabilidad ante los videojuegos, a partir de la autorregulación que realizan del tiempo dedicado y la elección por la que optan. De hecho, combinan de forma razonable la dedicación a estos juegos con la concedida al estudio, así como a otras responsabilidades o aficiones que le resultan agradables: ver la televisión, charlar, escuchar música, leer, etc.). Por el contrario, los chicos presentan una tendencia notoria en utilizar una elevada cantidad de tiempo con los videojuegos, aunque reconocen que le restan dedicación para desarrollar algunas actividades, que consideran de interés: realizar deporte, charlar, pasear, ir al cine, etc.).

A través de los resultados cualitativos se revela que el uso de los videojuegos desencadena algún conflicto familiar de pequeño calado, derivado de una amplia dedicación y del mal humor que le provoca en ocasiones. Estos son los problemas más comunes que se desprenden de esta práctica, independientemente del género de los participantes. De este modo, aunque de forma excepcional, también se presentan como las polémicas más destacadas para las chicas. Los adolescentes, hombres, demuestran poca preocupación por el hecho de dejar de realizar tareas escolares u otras actividades importantes, como por ejemplo estudiar o compartir su tiempo con los coetáneos, ante la fuerte inclinación que experimentan por los videojuegos; y son conscientes de que les distraen. A continuación se ofrece algún extracto ilustrativo:

Cuando juego estoy tan atenta que no presto atención al resto de cosas. Mi madre siempre se enfada conmigo cuando no hago lo que ella me pide mientras estoy jugando (grupo 2, línea 300-302, mujer, $2^{\circ} \mathrm{ESO}, 13$ años).

Algunas veces me olvido, jugando a los videojuegos, de cosas como quedar con los amigos o estudiar. Tengo también algún problema con mi familia por ellos y siempre me dicen que juego mucho (grupo 5, línea 177-179, hombre, $3^{\circ} \mathrm{ESO}, 14$ años).

\section{Discusión y conclusiones}

Del estudio realizado se desprende que la actividad de ocio más popular entre los adolescentes, además de salir con las amistades, es jugar con los videojuegos. A pesar de que existe una gran diversidad de este tipo de juegos, se revela que mantienen claras preferencias y que se produce una gran diferencia en el consumo, en función de la edad y del género. En este sentido, cabe resaltar que Moreno y García Serrano (2006) han señalado que las mujeres manifiestan ser mucho menos consumidoras que los hombres.

En cuanto a las preferencias por el tipo de dispositivo utilizado, de forma acentuada el colectivo muestra una notoria inclinación por la utilización de la consola. En particular en la actualidad por aquellas que le posibilitan jugar online. Estos dispositivos representan un enorme atractivo para los/as participantes al permitirles desarrollar el juego en tiempo real, principalmente, con sus amigos/as o coetáneos. Con todo, se producen importantes discrepancias por razón de género. En este sentido Arango, Bringué y Sábada (2010) sostuvieron que las chicas utilizan mayoritariamente los ordenadores, mientras que los chicos emplean la videoconsola. Sin embargo, de este estudio se desprende, que para jugar con los videojuegos, de modo secundario, los hombres optan por el ordenador y las mujeres por el móvil. Hay que tener en cuenta 
que este hallazgo, sobre el tipo de recurso utilizado, está supeditado a la propia emergencia de la tecnología y, a su vez, se encuentra subyugado a la modalidad de videojuego utilizado. De hecho, el Candy Crush, que es el más secundado por las adolescentes, está vinculado con dispositivos móviles (tipo smartphone) y se lanzó en 2012. La preferencia para compartir los videojuegos se topa supedita a las personas cercanas, principalmente a los amigos/as.

A pesar del elevado número de horas de dedicación del colectivo a los videojuegos las mujeres realizan un uso equilibrado, mientras que los hombres llegan a prestarle una desmesurada atención. Además, en el fin de semana se produce un aumento sustancial de su dedicación. En esta línea, también Marcano (2012) descubrió que el tiempo prestado a los videojuegos aumenta con creces los fines de semana. Por otra parte, en este trabajo se revela que la elevada dedicación de los/as adolescentes a los videojuegos se encuentra asociada a un escaso control de la familia sobre los hijos varones. Por otra parte, se ha detectado que son, en su mayoría, los adolescentes con calificaciones académicas más bajas, que se encuentra en los cursos más bajos $\left(1^{\circ}\right.$ y $2^{\circ}$ de la ESO), los que más tiempo dedican a este tipo de juegos.

En este estudio se han encontrado diferencias en las preferencias, atendiendo a la tipología de videojuegos, en base al género. Los chicos prefieren jugar a videojuegos de rol multi-jugador en línea. Cabe indicar que algunos de estos juegos (FIFA) están recomendados por el Pan European Game Information (PEGI). Su código recoge un sistema europeo de clasificación en base al contenido de los videojuegos y a las edades recomendadas para su utilización. Se trata de juegos que consiguen seducirles durante horas al presentar un fuerte atractivo por el modelo de acciones, principalmente, de carácter violento, que les permiten desarrollar. Por ello, es necesario que las familias y los educadores/as controlen y asesoren a los/as adolescentes para evitar problemas graves. De hecho, Huanca (2011) sostiene que jugar con videojuegos en Internet, en la adolescencia, genera anomalías en la personalidad y en el comportamiento. Como adelantamos, las mujeres optan por los videojuegos de estrategia como el de Candy Crush. Este videojuego aunque consigue el entretenimiento, no genera la misma intensidad en la excitación, como la que experimentan los adolescentes ante los de "mundo abierto", que también les lleva a una mayor dependencia.

En cuanto a las problemáticas derivadas de la utilización de los videojuegos, cabe indicar que no producen altercaciones sustanciales. De forma excepcional, algunos/as adolescentes presentan manifestaciones de mal humor cuando juegan. En este sentido se vislumbra sutilmente algún efecto adverso en los que dedican muchas horas a estos juegos. Independientemente de lo referido, la mayor parte de los/as participantes revelan comportamientos de cortesía, incluso cuando experimentan la derrota con el juego. Con todo, es recomendable mejorar la supervisión o control y la orientación, principalmente por parte de la familia. Cabe considerar que las personas adultas implicadas deben contar con formación para analizar el uso que pueden estar realizando de los videojuegos los/as adolescentes, con el objeto de prevenir las posibles problemáticas. En este sentido, es aconsejable la consulta del código PEGI. Además, cabe considerar que el aparato utilizado para los videojuegos no tiene porqué ser una variable que determine la tipología de altercados producidos. 
En otro orden de cuestiones, en casos excepcionales, los chicos que más tiempo pasan jugando son los que menos dedicación tienen al estudio. En un sentido similar, Luque y Aguayo (2013) asociaron la elevada frecuencia de exposición a videojuegos en la adolescencia con un bajo rendimiento escolar. En el presente estudio además se descubre que esta práctica intensificada temporalmente favorece la creación de algún conflicto familiar coligado con lo anterior, independientemente del género del colectivo.

Del estudio realizado se desprende que las prácticas con los videojuegos en la adolescencia se ciñen al mero hecho de divertirse, desperdiciándose las posibilidades educativas que estos medios ofrecen. Por ello, para que los/as adolescentes puedan beneficiarse plenamente de esta praxis es necesario un cambio en sus formas de uso. Hay que tener en cuenta, siguiendo a Moreno y García Serrano (2006), que estas actividades poseen un gran potencial para el desarrollo de diferentes competencias.

\section{Limitaciones y prospectiva}

Los hallazgos aportados posibilitan un mejor conocimiento de la realidad, a partir de su análisis y comprensión. Con todo ante las características y complejidad del tópico abordado es conveniente en el futuro continuar profundizando en los propósitos de esta investigación, así como ampliar la perspectiva del estudio incluyendo, además del alumnado, al profesorado y a las familias. Asimismo, es conveniente incluir un mayor número de técnicas o instrumentos en la recogida de información.

Hay que tener en cuenta que la inclusión curricular de los videojuegos puede contribuir a mejorar el interés en el alumnado por el aprendizaje. Por ello, aunque excedía la amplitud de esta investigación resulta apropiado indagar en el futuro sobre este aspecto, tanto por las ilaciones académicas positivas que desencadene, como por su posible contribución al desarrollo global de los/as adolescentes. De este modo, es oportuno abordar el diseño e implementación de un programa en el marco de la investigación-acción, que integre los videojuegos en el contexto escolar para tratar de incrementar la motivación por el aprendizaje del alumnado, mejorar el desarrollo de sus competencias y, en consecuencia, aumentar su rendimiento académico. Esto será factible fundamentalmente a través de un proceso reflexivo y colaborativo (implicando, en lo posible, a toda la comunidad educativa) que enlace la investigación desde la práctica con la propia acción y su evaluación (considerando el análisis del proceso y de los resultados obtenidos con el programa). Previsiblemente, este tipo de diseño permitirá ampliar los hallazgos sobre la temática suponiendo un valor añadido para el contexto educativo. 


\section{Referencias bibliográficas}

ANDERSON, C., IHORI, N., BUSHMAN, B. Y ROTHSTEIN, H. (2010). Violent video game effects on aggression, empathy, and prosocial behavior in eastern and western countries: A meta-analytic. Review Psychological Bulletin, 136 (2), 151173.

ARANGO, G., BRINGUÉ, X. Y SÁBADA, C. (2010). La generación interactiva en Colombia: adolescentes frente a la Internet, el celular y los videojuegos. Anagramas, 9,(17), 45-56.

FERRER, M. Y RUÍZ, J. A. (2005). Uso de videojuegos en niños de 7 a 12 años. Una aproximación mediante encuesta. Icono14, 7, 1-15.

GARRIDO, J. M. (2013). ¿Por qué los estudiantes juegan con videojuegos de estrategia?: Algunos principios para la enseñanza. Revista Electrónica de $\begin{array}{lllll}\text { Investigación } & \text { Educativa, } & 15 & \text { 62-74. }\end{array}$ http://redie.uabc.mx/index.php/redie/article/view/330/515 (Consultado 14 de noviembre de 2014).

GÓMEZ DEL CASTILLO, M. T. (2007). Videojuegos y transmisión de valores. Revista Iberoamericana de Educación, 43 (6), 1-10.

GRIFFITHS, M., DAVIES, M. Y CHAPPELL, D. (2004). Demographic factors and playing variables in online computer gaming. CyberPsichology \& Behavior, 7 (4), 479-488.

HART, G., JOHNSON, B., STAMM, B., ANGERS, N., ROBINSON, A., LALLY, T. Y FAGLEY, W. (2009). Effects of video games on adolescens and adults. CyberPsychology \& Behavior, 12 (1), 63-65.

HUANCA, F. (2011). Influencia de los juegos de Internet en el comportamiento de los adolescentes de la ciudad de Puno. Revista de Investigación en Comunicación y Desarrollo, 2 (2), 37-44.

HUIZINGA, J. (2007). Homo Ludens. Madrid: Alianza.

HUSSAIN, Z. Y GRIFFITHS, D. (2009). The attitudes, feelings, and experiences of online gamers: A qualitative analysis. CyberPsychology \& Behacior, 12 (6), 747753.

LORCA, M.A. (2006). Los videojuegos, marcadores de tendencias en el ocio tecnológico. Comunicar, 27, 79-84.

LUQUE, A. T. Y AGUAYO, L. V. (2013). Factores moduladores de la respuesta agresiva tras la exposición a videojuegos violentos. Revista Anales de Psicología, 29 (2), 311-318.

LLORET, D., CABRERA, V. Y SANZ, Y. (2013). Relaciones entre hábitos de uso de videojuegos, control parental y rendimiento escolar. European Journal of Investigation in Health, 3 (3), 237-248. 
MARCANO, B. (2012). Características sociológicas de videojugadores online y el esport. El caso de Call of duty. Pedagogía Social. Revista Interuniversitaria, 19, 113-124.

MARCO, C. Y CHÓLIZ, M. (2014). Tratamiento cognitivo-conductual de la adicción a videojuegos de rol online: fundamentos de propuesta de tratamiento y estudio de caso. Anales de Psicología, 30 (1), 46-55.

MARÍN, V. Y PÁRRAGA, J. M. (2014). Can videogames be used to develop the infant stage educational curriculum? New Approaches in Educational Research, 3 (1), 20-25.

MINISTERIO DE EDUCACIÓN Y CIENCIA (2004). Informe Videojuegos $y$ Educación. Madrid: Grupo de Investigación sobre Videojuegos de la Universidad de Málaga.

MÖßLE, T., KLEIMANN, M., REHBEIN, F. Y PFEIFFER, C. (2010). Media use and school achievement-boys at risk? British Journal of Developmental Psychology, 28 (3), 699-725.

MUROS, B., ARAGÓN, Y. Y BUSTOS, A. (2013). La ocupación del tiempo libre de jóvenes en el uso de videojuegos y redes. Comunicar, 40, 31-39.

MORENO, I. Y GARCÍA SERRANO, J. A. (2006). Las nuevas pantallas, un reto educativo. Revista Complutense de Educación, 17 (1), 135-149.

PÉREZ LATORRE, O. (2010). Análisis de la sinificación del videojuego. Fundamentos teóricos del juego, el mundo narrativo y la enunciación interactiva como perspectivas de estudio del discurso (tesis doctoral). Barcelona: Universitat Pompeu Fabra.

REDICK, T. Y WEBSTER, S. (2014). Videogame interventions and spatial ability interactions. Frontiers in Human Neuroscience, 8 (183), 1-5.

SAUQUILlO, P., ROS, C. Y BELLVER, M. C. (2008). El rol de género en los videojuegos. Teoría de la Educación y Cultura en la Sociedad de la Información, 9 (3), 130-149.

SHARIF, I., WILLS, T. A. Y SARGENT, J. D. (2010). Effect of visual media use on school performance: A prospective study. Journal of Adolescent Health, 46 (1), 5261 .

TEJEIRO, R. Y PELEGRINA, M. (2003). Los Videojuegos. Qué son y cómo nos afectan. Barcelona: Ariel.

TOLSÁ, J. Y BRINGUÉ, X. (2012). Leisure, interpersonal relationships, learning and consumption: the four key dimensions for the study of minors and screens. Comunicación y Sociedad, 25 (1), 253-287.

TRACY, S. J. (2010). Qualitative Quality: Eight "Big-Tent" Criteria for Excellent Qualitative Research. Qualitative Inquiry, 16 (10) 837-851. 
WARD, M. (2010). Videogames and crime. Contemporary Economic Policy, 29 (2), 261-273.

WITTGENSTEIN, L. (2008). Investigaciones filosóficas. Barcelona: Crítica.

\section{Correspondencia con las autoras}

María-Carmen RICOY

Facultad de CC. de la Educación

Universidad de Vigo

Avd/ Castelao, s/n 32004 Ourense (España)

e-mail: cricoy@uvigo.es

\section{Aida AMENEIROS}

Facultad de CC. de la Educación

Universidad de Vigo

Avd/ Castelao, s/n 32004 Ourense (España)

e-mail: aidaameneiros@uvigo.es 